\title{
The dilemma of functional therapy: the new EFA to do or not to do?
}

\author{
Omnia A. Elhiny ${ }^{1 *}$ (D) and Mohamed I. El-Anwar ${ }^{2}$
}

\begin{abstract}
Objectives: This finite element analysis was conducted to study the effects produced by a new fixed functional appliance (EFA; Elhiny functional appliance) and hence predict its clinical effectiveness.

Materials/methods: Under ANSYS environment, a simplified 2D finite element model was prepared for this study. The models simulated a clinical situation where the mandible was positioned forward via a new fixed functional appliance design. The models' components were created on a commercial CAD/CAM package then imported to finite element software. Pushing load of $2 \mathrm{~N}$ was applied along the appliance longitudinal direction.

Results: The mandible showed downward and forward deformation in the $X$ and $Y$ directions with the highest deformation at the symphysis and lower border with a total deformation of $80 \mu \mathrm{m}$. There was little deformation in the maxilla. The highest strain results were at the condyle, both compressive and tensile in the $X$ and $Y$ directions with a total of 1520 micro strain behind the condyle. The strain in the mandibular tooth bearing area was around zero and in the maxillary tooth bearing area ranged from -9 to 16.6 micro strain.

Conclusions: Within the limitations of this finite element analysis, it could be predicted that the new appliance (EFA) produces pure functional skeletal results with absolutely no dentoalveolar effects, which provides the opportunity for observing significant skeletal changes.
\end{abstract}

Keywords: Finite element analysis, Fixed functional appliances, Biomechanical effects, Mandibular growth

\section{Introduction}

The skeletal effect of functional therapy on the mandible is a highly debatable subject that is yet unresolved. Many trials and systematic reviews have been made in a quest to find whether functional appliances have a skeletal effect on the mandible or is it merely the dentoalveolar compensation that corrects the discrepancy.

Some researchers assert the presence of favorable mandibular growth represented by condylar and glenoid fossa remodeling (Ruf and Pancherz 1999; Rabie and Hägg 2003; Antonarakis and Kiliaridis 2007; Paulsen et al. 1995; McNamara Jr and Howe 1990; Franchi et al. 1999; Woodside et al. 1987). Such remodeling resulted from the acceleration of chondrocytic differentiation and the increase in the amount of cartilage matrix formation, hence enhancing growth (Rabie and Hägg 2003).

\footnotetext{
* Correspondence: omniaelhiny@yahoo.com

${ }^{1}$ Orthodontics and Pediatric Dentistry Department, National Research Centre,

33 El Bohouth St., Dokki, P.O. 12622, Cairo, Egypt

Full list of author information is available at the end of the article
}

On the other hand, some researchers argue about the significance of the magnitude of such skeletal effects and point to the evidence showing the distinction of the dentoalveolar changes produced (Cozza et al. 2006; Franchi et al. 2011; Zymperdikas et al. 2016; Marsico et al. 2011; Cope et al. 1994; Darda et al. 2010; Küçükkeleș et al. 2007). However, these dentoalveolar changes may in turn have acted as a restraint to the full expression of the skeletal enhancement.

It then appears that to be able to ascertain or negate the presence of significant skeletal changes with functional therapy, it was necessary to rule out the dentoalveolar factor through modifying the appliance design.

Consequently, this finite element analysis was conducted to study the effects produced by a newly devised fixed functional appliance (EFA; Elhiny functional appliance) and hence predict its clinical effectiveness. 


\section{Materials and methods}

The current finite element analysis simulated a clinical situation where the mandible was positioned forward via a new fixed functional appliance design, EFA. The appliance could be easily constructed in the laboratory.

A two-dimensional model was prepared on ANSYS GUI, to simulate the lower part of the skull. The model dimensions were taken from literature (Panigrahi and Vineeth 2009). Two types of elements were used to build the model: Shell 3D 4node 181 with 6 degrees of freedom to mesh the bone and Link 180 as spar element to represent the appliance effect (Kohnke 2013). The applied force was $2 \mathrm{~N}$ propulsive force, as the forces generated by fixed functional appliances range from 150 to 200 g, i.e., 1.47 to $1.98 \mathrm{~N}$ (Karacay et al. 2006; Nalbantgil et al. 2005). The meshing process resulted in 59,386 nodes and 30,459 elements. As presented in Fig. 1, after the model meshing, the upper line, connecting the model to the skull, was set fixed in place as boundary condition.

All materials were assumed to be isotropic, homogenous, and linearly elastic, and their properties were listed in Table 1.

Linear static analysis was performed on a personal computer (Intel Core to Due processor, 2.8 GHz, 4.0 GB RAM), using commercial multipurpose finite element software package (ANSYS version 13.0). The deformation and strain results were analyzed and represented graphically.

\section{Results}

The mandible showed forward and downward deformation, in both $X$ and $Y$ directions (Fig. 2).

The mandibular symphysis showed the highest deformation in the $Y$ direction, and the symphysis and

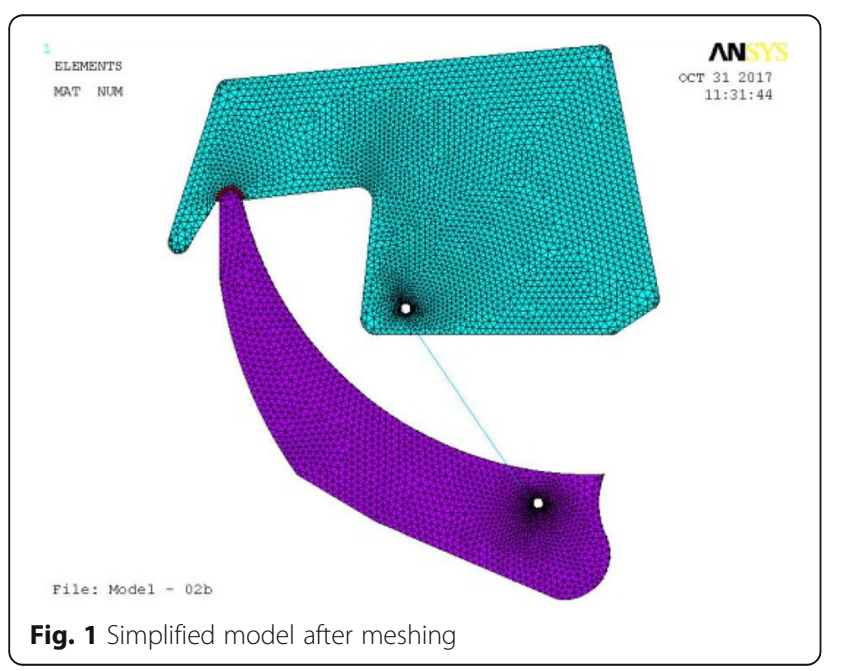

Table 1 Properties of materials used in the finite element model

\begin{tabular}{lll}
\hline Material & Young's modules [GPa] & Poisson's ratio \\
\hline Condyle & 0.065 & 0.34 \\
Bone & 13.7 & 0.30 \\
\hline
\end{tabular}

lower border in the $X$ direction. As illustrated in Fig. 2, the maximum horizontal deformation in the mandible was $9.3 \mu \mathrm{m}$, while the vertical deformation was of order $7.2 \mu \mathrm{m}$. The total deformation at the symphysis was $80 \mu \mathrm{m}$.

The maxilla showed very little deformation upwards in the $Y$ direction (about $0.13 \mu \mathrm{m}$ ), in the area representing point A and the anterior nasal spine (ANS). While in the $X$ direction, there was an even less backward than the upward deformation, about $0.016 \mu \mathrm{m}$.

The condylar strain results in Fig. 3 showed that the strain in the $X$ direction was a compressive strain of about 1122 micro strain anterior to the condyle, and 122 tensile micro strain behind the condyle. Above the condylar head, the strain ranged from -71 to +191 micro strain. While in the $Y$ direction, the strain ranged from 150 to 170 micro strain behind the condyle, from 260 to 395 micro strain in front of the condyle, and an average of 940 micro strain above the condyle. The total condylar strain was about 1520 micro strain behind the condyle.

The mandibular strain increased gradually in the $X$ direction from -70 to +13 micro strain and in the $Y$ direction from -9 to +23 micro strain. A stress/strain concentration appeared around the point of force application, where in the $X$ direction the strain was about 677 micro strain and in the $Y$ direction it was approximately 86 micro strain. Hence, the total mandibular strain ranged from 0 to 166 micro strain with an average of 150 micro strain at the point of force application. On the other hand, at the tooth bearing area, the strain was approximately zero (Fig. 4).

As presented in Fig. 5, the strain in the glenoid fossa in the $Y$ direction was around 5.3 to 6.9 micro strain, while the total glenoid fossa strain ranged from 5.6 to 11.2 micro strain whereas the strain in the $X$ direction, in the maxillary tooth bearing area, ranged from -9 to 16.6 micro strain and the total maxillary strain ranged from 0 to 50 micro strain.

\section{Discussion}

There has been a wide debate regarding the output of using functional appliances, removable or fixed, for mandibular advancement. In noncompliant and post pubertal patients, the fixed functional appliance was the 


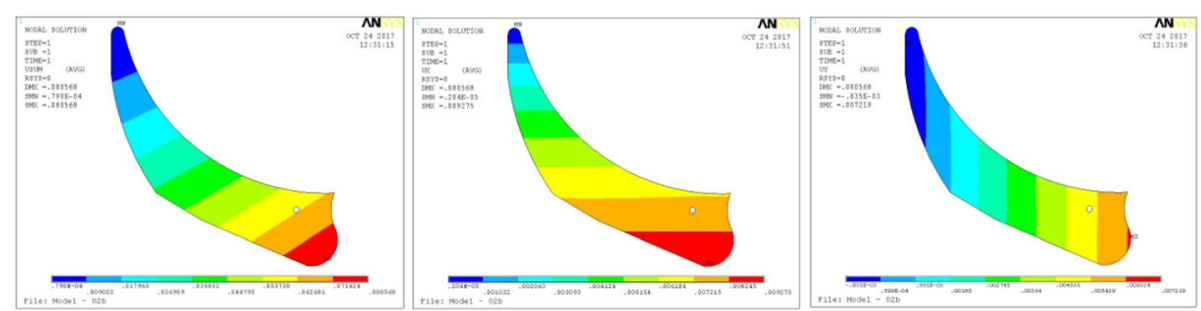

Fig. 2 Total deformation in the mandible and its components in horizontal and vertical directions

only successful non-surgical treatment (Panigrahi and Vineeth 2009). However, the main issue was the prevalence of dentoalveolar effects over skeletal effects (Cozza et al. 2006; Franchi et al. 2011; Zymperdikas et al. 2016; Marsico et al. 2011; Cope et al. 1994; Darda et al. 2010; Küçükkeleş et al. 2007; Panigrahi and Vineeth 2009; Nalbantgil et al. 2005).

As a result, it was hypothesized, in the current study, that by modifying the fixed functional appliance design into the new Elhiny functional appliance (EFA) design, the dentoalveolar effect would be either reduced or ruled out and the presence or absence of a significant skeletal effect could be discriminated.

The deformation in finite element analysis indicates that a change in size, and accordingly movement, has occurred. In clinical practice, the desirable effects for the correction of class II skeletal malocclusion are enhancing the mandibular growth while restraining the maxillary growth (Antonarakis and Kiliaridis 2007; Vargervik and Harvold 1985; Harvold and Vargervik 1971; Pancherz 1982; Macey-Dare and Nixon 1999; Collett 2000). Similar results were reported in this study; the greatest movement occurred in the forward and downward direction at the symphysis and lower border of the mandible. This was associated with a little backward and upward deformation in the maxilla indicating that some restraining effect was demonstrated as well (Nalbantgil et al. 2005). The low deformation values observed at the condyle suggest the absence of pain during treatment.
Different studies in the literature discussed the effects of stress and stress distribution on the condyle and the glenoid fossa and how the tensile and compressive stresses created by mandibular advancement resulted in remodeling (Panigrahi and Vineeth 2009; Rabie et al. 2001; Rabie et al. 2003a; Sato et al. 2005; $\mathrm{Hu}$ et al. 2001; Zhou et al. 1999; Ress 1954). However, there was no known reference value for the optimal physiological range of stresses (Panigrahi and Vineeth 2009). It was apparent then, as there were reported values for strain in the literature, that it was the optimum parameter to be investigated even though there were no comparable studies considering strain. It was previously reported that the strain values that resulted in physiological bone modeling and remodeling ranged from 100 to 3000 micro strain (EL- Zawahry et al. 2016), and strains from 3600 to 4000 micro strain were considered within the physiological range in living animals (Sugiura et al. 2000).

Owtad et al. reported that the biophysical changes that occur as a result of mandibular advancement prompt cellular and molecular changes which result in bone formation and condylar growth enhancement (Owtad et al. 2011). These cellular changes could be as a result of the genetic expression of Sox 9 and type II collagen leading to merely an acceleration of the genetically predetermined growth. However, Rabie et al. demonstrated that the expression of such factors did not result in a change in the normal growth pattern; thus, functional therapy could induce true

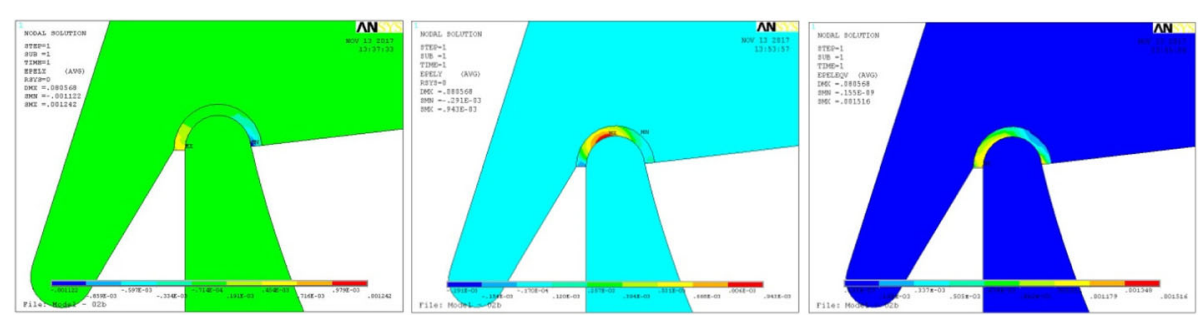

Fig. 3 Condylar strain in $X$ and $Y$ directions and total strain 


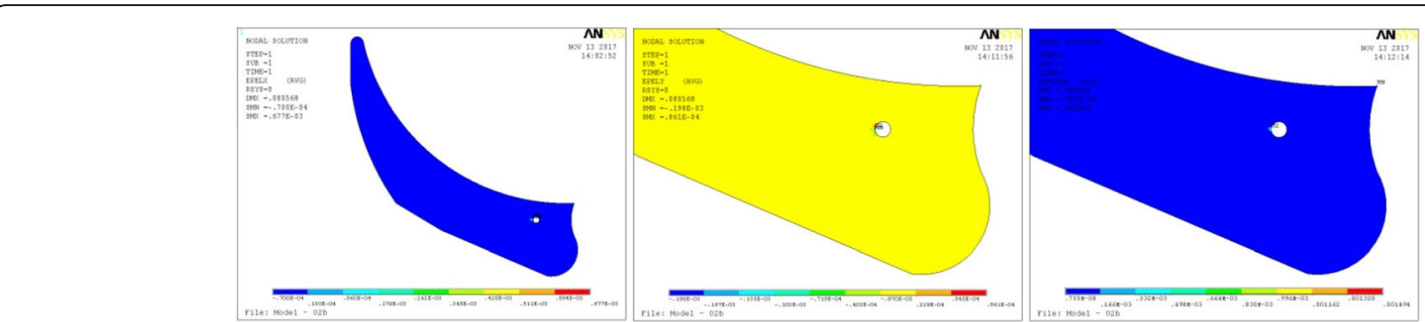

Fig. 4 Mandibular strain in $X$ and $Y$ directions and total strain

condylar growth augmentation (Rabie et al. 2003b). On analyzing the strain results in this study, it was deduced that there was physiologic adaptive remodeling in the mandibular condyle in all directions, and mandibular forward and downward movement was demonstrated.

Different growth theories that explained the mechanism of growth modification described that functional adaptation occurred harmoniously in the condyle and the glenoid fossa, yet differently, and contributed to the growth modification process (Voudouris et al. 2003). The growth relativity hypothesis explained that the viscoelastic forces applied during functional therapy resulted in growth remodeling in the TMJ complex, which depended on the balance among many factors (Voudouris et al. 2003; Voudouris and Kuftinec 2000).

On the other hand, the ratchet hypothesis proposed that the condyle was the utmost determinant of the mandibular downward and forward movement (Whetten and Johnston Jr 1985). Others also reported that the role of the condyle in the process was exceptionally higher than the glenoid fossa (Owtad et al. 2011; Barnouti et al. 2011), which conformed to the results of this study in which condylar remodeling was considerably higher, and in contrast to some studies which reported remarkable glenoid fossa adaptation (McNamara Jr et al. 2003).

Contrary to all previous clinical reports (Cozza et al. 2006; Franchi et al. 2011; Zymperdikas et al. 2016; Marsico et al. 2011; Cope et al. 1994; Darda et al.
2010; Küçükkeleş et al. 2007; Panigrahi and Vineeth 2009; Nalbantgil et al. 2005), there was no movement in the mandibular dentoalveolar area at all as the observed strain at the tooth bearing area was an average of zero. Similarly, no maxillary dentoalveolar movement was demonstrated.

Accordingly, it could be predicted that the new design would enhance mandibular forward and downward growth without resulting in any dentoalveolar compensations. The absence of such compensations provides the opportunity for observing the presence or absence of significant skeletal changes with functional therapy.

\section{Conclusion}

Within the limitations of this finite element analysis, it was concluded that the new Elhiny fixed functional appliance design (EFA) resulted in:

- Mandibular forward and downward movement, apparent at the mandibular symphysis and the lower border of the mandible

- Physiological remodeling at the condyle, indicative of condylar growth

- No dentoalveolar movement

Hence, it could be predicted that the new appliance (EFA) produces pure functional skeletal results with absolutely no dentoalveolar effects. The absence of dentoalveolar effects might allow the full expression of growth.

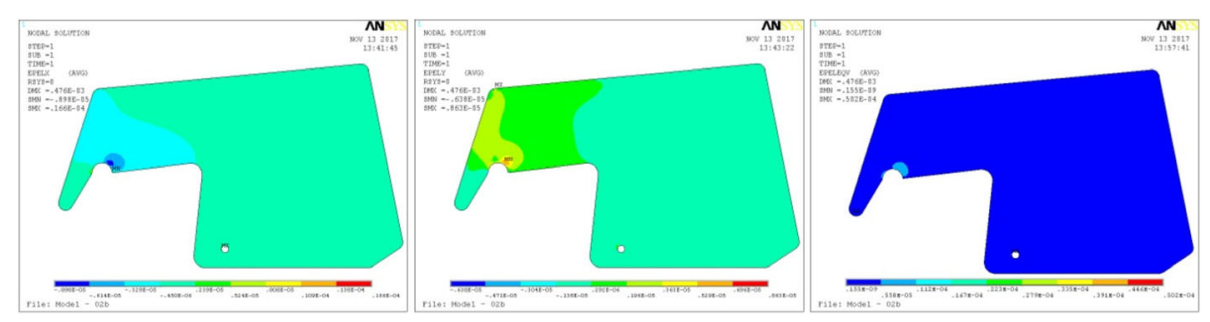

Fig. 5 Maxillary strain in $X$ and $Y$ directions and total strain 
Furthermore, it can be useful in cases with deficient mandibular growth, increased overjet, proclined lower incisors, and/or retroclined upper incisors.

\section{Recommendations}

Clinical studies should be conducted on the newly designed appliance.

\section{Acknowledgements}

Not applicable

\section{Funding}

Not applicable

\section{Availability of data and materials}

All data generated or analyzed during this study are included in this published article.

\section{Authors' contributions}

OE came up with the idea of the appliance and research, interpreted the engineering data orthodontically, and was a major contributor in writing the manuscript. ME designed the study methodology, analyzed and interpreted the data from the engineering point of view, and contributed in writing the manuscript. All authors read and approved the final manuscript.

\section{Ethics approval and consent to participate}

Not applicable

\section{Consent for publication}

Not applicable

\section{Competing interests}

The authors declare competing interests as one of them has applied for a patent.

\section{Publisher's Note}

Springer Nature remains neutral with regard to jurisdictional claims in published maps and institutional affiliations.

\section{Author details}

'Orthodontics and Pediatric Dentistry Department, National Research Centre, 33 El Bohouth St., Dokki, P.O. 12622, Cairo, Egypt. ${ }^{2}$ Mechanical Engineering Department, National Research Centre, Cairo, Egypt.

Received: 20 June 2018 Accepted: 29 October 2018

Published online: 20 November 2018

\section{References}

Antonarakis GS, Kiliaridis S (2007) Short-term anteroposterior treatment effects of functional appliances and extraoral traction on class II malocclusion. Angle Orthod 77(5):907-914.

Barnouti ZP, Owtad P, Shen G, Petocz P, Darendeliler MA (2011) The biological mechanisms of PCNA and BMP in TMJ adaptive remodeling. Angle Orthod 81:91-99.

Collett AR (2000) Current concepts on functional appliances and mandibular growth stimulation. Aust Dent J 45:173-178.

Cope JB, Buschang PH, Cope DD, Parker J, Blackwood HO 3rd (1994) Quantitative evaluation of craniofacial changes with Jasper Jumper therapy. Angle Orthod 64(2):113-122.

Cozza P, Baccetti T, Franchi L, De Toffol T, McNamara JA Jr (2006) Mandibular changes produced by functional appliances in class II malocclusion: a systematic review. Am J Orthod Dentofac Orthop 129(5):1-4

Darda M, Goel S, Gupta R (2010) A cephalometric comparison of the dentoskeletal changes in class II malocclusion by using Jasper Jumper and Forsus - a clinical study. IJCD 1(2):79-86.

EL- Zawahry MM, EL- Anwar MI, EL-Mofty MS, EL-Ragi AH, Moussa AR, ElGabry HS, Shebaita AM (2016) Implant angulations effect on bone stresses: clinical and FEA study. RJPBCS 7(3):2448.

Franchi L, Alvetro L, Giuntini V. Masucci C. Defraia E, Baccetti T (2011) Effectiveness of comprehensive fixed appliance treatment used with the
Forsus fatigue resistant device in class II patients. Angle Orthod 81(4): 678-683.

Franchi L, Baccetti T, McNamara JA Jr (1999) Treatment and posttreatment effects of acrylic splint Herbst appliance therapy. Am J Orthod Dentofac Orthop 115(4):429-438.

Harvold EP, Vargervik K (1971) Morphogenetic response to activator treatment. Am J Orthod 60:478-490

Hu L, Zhoo Z, Song J, Fan Y, Jiang W, Chen J (2001) The influences of the stress distribution on the condylar cartilage surface by Herbst appliance under various bite reconstruction - a three dimensional finite element analysis. Hua Xi Kou Qiang Yi Xue Za Zhi 19(1):46-48.

Karacay S, Akin E, Huseyin A, Umit G, Sagdic D (2006) Forsus nitinol flat spring and Jasper Jumper correction of class II division 1 malocclusion. Angle Orthod 76:666-672.

Kohnke P (2013) ANSYS mechanical APDL theory reference. ANSYS Inc, Canonsburg.

Küçükkeleş N, Ihan I, Orgun IA (2007) Treatment efficiency in skeletal class II patients treated with the jasper jumper. Angle Orthod. 77(3):449-456.

Macey-Dare LV, Nixon F (1999) Functional appliances: mode of action and clinical use. Dent Update 26:240-244 246.

Marsico E, Gatto E, Burrascano M, Matarese G, Cordasco G (2011) Effectiveness of orthodontic treatment with functional appliances on mandibular growth in the short term: systematic review. Am J Orthod Dentofacial Orthop Jan 139( 1:24-36.

McNamara JA Jr, Howe RP, Dischinger TG (1990) A comparison of the Herbst and Fränkel appliances in the treatment of class II malocclusion. Am J Orthod Dentofac Orthop 98(2):134-144

McNamara JA Jr, Peterson JE Jr, Pancherz H (2003) Histologic changes associated with the Herbst appliance in adult rhesus monkeys (Macaca mulatta). Semin Orthod 9:26-40.

Nalbantgil D, Arun T, Sayinsu K, Isik F (2005) Skeletal, dental and soft tissue changes induced by Jasper Jumper appliance in late adolescence. Angle Orthod. 75:426-436.

Owtad P. Potres Z, Shen G, Petocz P. Darendeliler MA (2011) A histochemical study on condylar cartilage and glenoid fossa during mandibular advancement. Angle Orthod 81:270-276.

Pancherz H (1982) The mechanism of class II correction in Herbst appliance treatment: a cephalometric investigation. Am J Orthod 82:104-113.

Panigrahi P, Vineeth V (2009) Biomechanical effects of fixed functional appliance on craniofacial structures. Angle Orthod 79(4):668-675.

Paulsen HU, Karle A, Bakke M, Herskind A (1995) CT-scanning and radiographic analysis of temporomandibular joints and cephalometric analysis in a case of Herbst treatment in late puberty. Eur J Orthod 17(3):165-175.

Rabie AB, Hägg U (2003) Functional appliance therapy accelerates and enhances condylar growth. Am J Orthod Dentofac Orthop 123(1):40-48.

Rabie AB, She TT, Hägg U (2003b) Functional appliance therapy accelerates and enhances condylar growth. Am J Orthod Dentofac Orthop 123:40-48.

Rabie AB, She TT, Harley VR (2003a) Forward mandibular positioning up-regulates SOX9 and type II collagen expression in the glenoid fossa. J Dent Res 82 $725-730$

Rabie AB, Zhao Z, Shen G, Hägg EU, Robinson W (2001) Osteogenesis in the glenoid fossa in response to mandibular advancement. Am J Orthod Dentofac Orthop 119:390-400.

Ress LA (1954) Structures and function of the mandibular joint. Br Dent J 96 $125-133$

Ruf S, Pancherz H (1999) Dentoskeletal effects and facial profile changes in young adults treated with the Herbst appliance. Angle orthod 69(3):239.

Sato K, Adachi T, Matsuo M, Tomita Y (2005) Quantitative evaluation of threshold fiber strain that induces reorganization of cytoskeletal actin fiber structure in osteoblastic cells. J Biomech 38:1895-1901.

Sugiura T, Horiuchi K, Sugimura M, Tsutsumi S (2000) Evaluation of threshold stress for bone resorption around screws based on in vivo strain measurement of miniplate. Musculoskelet Neuronal Interact 1(2):165-170

Vargervik K, Harvold EP (1985) Response to activator treatment in class II malocclusions. Am J Orthod 88:242-251.

Voudouris JC, Kuftinec MM (2000) Improved clinical use of Twin-block and Herbst as a result of radiating viscoelastic tissue forces on the condyle and fossa in treatment and long-term retention: growth relativity. Am J Orthod Dentofac Orthop 117:247-266.

Voudouris JC, Woodside DG, Altuna G, Kuftinec MM, Angelopoulos G, Bourque PJ (2003) Condyle-fossa modifications and muscle interactions during Herbst 
treatment, part 1. New technological methods. Am J Orthod Dentofacial Orthop 123:604-613.

Whetten LL, Johnston LE Jr (1985) The control of condylar growth: an experimental evaluation of the role of the lateral pterygoid muscle. Am J Orthod 88:181-190

Woodside DG, Metaxas A, Altuna G (1987) The influence of functional appliance therapy on glenoid fossa remodeling. Am J Orthod Dentofac Orthop 92(3): 181-198.

Zhou X, Zhoo Z, Zhao M (1999) Analysis of the condyle in the state of mandibular protraction by means of the three dimensional finite element method. Zhon Ghua Kou Quiang Yi Xue Za Zhi 34(2):85-87.

Zymperdikas VF, Koretsi V, Papageorgiou SN, Papadopoulos MA (2016) Treatment effects of fixed functional appliances in patients with class II malocclusion: a systematic review and meta-analysis. Eur J Orthod 38(2):113-126.

\section{Submit your manuscript to a SpringerOpen ${ }^{\circ}$ journal and benefit from:}

- Convenient online submission

- Rigorous peer review

- Open access: articles freely available online

- High visibility within the field

- Retaining the copyright to your article

Submit your next manuscript at $\boldsymbol{\nabla}$ springeropen.com 